\title{
Case Study: The University of Teesside Learning Resource Centre: Access to Knowledge, Imagination \& Learning
}

\author{
by IAN C. BUTCHART
}

The University of Teesside is located in Middlesbrough, a major North East town at the heart of the Teesside region. Over 14,000 students are currently studying at Teesside on a range of courses, from diplomas and first degrees to postgraduate qualifications. The University's $£ 11$ mill. Learning Resource Centre is at the heart of the Teesside learning experience and is a landmark for the region.

Mo Mowlam, the then Secretary of State for Northern Ireland, but more importantly our local Member of Parliament opened the University of Teesside Learning Resource Centre (LRC) in January 1998. At the opening ceremony she unveiled a plaque which had the inscription Access to Knowledge, Imagination and Learning. This title is taken from a United Kingdom government report, which focussed on the need to develop Public Libraries to deliver the full range of printed and electronic information materials for the general public. It may seem strange that a University Librarian should draw on such a source as the visionary statement of what the new Learning Resource Centre represented for the University. However that Report itself is a vibrant reminder of how powerful an influence all libraries are for the public good and that the University of Teesside is firmly committed to its local community and ensuring that they have a Higher Education Institution that is not an ivory tower but wishes to enable all learners to gain Access to Knowledge, Imagination and Learning. The opening ceremony was therefore a major opportunity to state publicly that this building was a major improvement for our staff and students but also a significant investment in the continuing development of Teesside as a ,Learning Region'. As the Opportunity University we wished to demonstrate our commitment to the regeneration of Teesside. 
Bill Cowan has demonstrated in his description of the United Kingdom Learning Resource Centre movement the changing higher education needs for access to information. He rightly stressed the importance of the brief and the working relationship between client and architect that influenced FaulknerBrowns design of the building. Our work together strongly influenced the design of the Teesside LRC as a powerful symbol that has been used to change our own staff's perception of the new learning and research agenda and to influence local and national partners perceptions of the University. I wish to illustrate this in four specific aspects. These are:

- First and foremost to have a building that would contribute to the learning infrastructure and meet the needs of our staff and students;

- a building which would be a Landmark in the University's development and growing maturity. A symbol that we were a major contributor to the Teesside Community and had provided a building that would engender civic pride;

- the impact of student behaviour on the study environment in a Learning Resource Centre;

- finally to provide a working environment for Library \& Information Service staff that would encourage a common culture focussed on providing learning resource services and facilities.

\section{THE LEARNING INFRASTRUCTURE}

When we began to plan the Learning Resource Centre in 1994 we recognised that our staff and students would require easy and flexible access to the wide range of print and electronic services that were becoming available. It was to be a place of study that supported a University culture, which demanded disciplined thinking, encouraged curiosity, challenged existing ideas and generated new ones. These ideas include the recognition that no one building could be a single repository of information for learning, teaching and research; information was available through many different media and many different locations. The size of the bookstock was not to be a major factor; we would continue with a policy of access and not collection. Globalisation was not then an overt influence nor the Internet yet we recognised that we needed a building for current and future needs. This would provide the opportunities for learning offered by Information and Communications Technologies; in doing so we did not reject the robust and long lasting value of the book. It was after all one of our earliest technologies. 
The library building at that time had 504 reader spaces, 13 public computers, opened for 67 hours per week, was dark and dingy, and the air conditioning had collapsed. Our preliminary survey described it as having a structure similar to a multi-storey carpark. The Library in 1993 was perceived as a major weakness in feedback from students, examination boards, and external assessors. For example the Higher Education Funding Council (England) requires all University's to produce a definitive statement of its Learning and Teaching Strategies. The HEFCE Quality Assessment of business and management studies had identified there is great pressure on library reader space and book provision and the rights to use this library by franchised students are limited. Such assessments include the measurement of the Learning Resources aspect. For this we were receiving marks of $2 / 3$ out of a possible 4 . We were not providing an excellent student learning experience and we were undermining the work of our academic colleagues and losing their respect.

The new building has 1,307 reader spaces, 400 electronic workspaces, and is open for 87 hours per week. It is light and airy and since its opening we have received straight 4's in Quality Assessment visits. More importantly the new building has regained our credibility with academic staff and enabled us to be full partners in developing the emerging learning, research and enterprise strategies of the Millennium. Thus the University's Learning, Teaching and Assessment Strategy 1999 - 2003 articulates the concept of the ,Teesside Learning Experience' with its emphasis on the move from the dependent to the independent learner and the development of personal and transferable skills as well as subject knowledge. On its first page it states that:

„Since 1995 the University has made a significant commitment in pursuing the achievement of the underlying principles and priorities of the original TLAS and has committed significant resources in this area through such initiatives as the

- Construction of the University's new Learning Resource Centre."

From a position of weakness we are seen as a major contributor to the University's excellence.

\section{A LANDMARK BUILDING}

The educational foundation of the University commenced in 1929 with the opening of Constantine College in 1929. This was on a prime site in the town of Middlesbrough and became a recognised local landmark. The town itself 
had a fine range of Victorian Buildings, but many of these were swept away in the redevelopment of the 1960's. The University itself had in the 60's and 70's built a range of educational buildings including an educational tower block and a purpose built library. None of these were distinguished architecturally and were not particularly visible within Middlesbrough. It was possible to visit the town and be unaware that there was a University presence. The University's Estate Strategy in addressing this issue commenced a major redevelopment under the slogan of Campus 2000 and used this to market the University in fund raising initiatives. The proposed Learning Resource Centre was seen as a significant ,brand leader' with its emphasis on Information and Communications technology and drew upon our national reputation in Computing Studies and Virtual Reality. We were successful in bidding for Government Funds and the building opened in September 1997. It has proved a success in raising the profile of the University in the local community. The local Newspaper reported thus:

„Forget the Millennium Dome. If you are looking for a symbol of architecture to catapult Britain into the $21^{\text {st }}$ Century, you need to look no further than our own doorstep. Beautiful, graceful and futuristic in style, the glass-fronted superstructure on Southfield Road is one of the most significant additions to Middlesbrough skyline since the Cellnet Riverside Stadium."

Perhaps some elements of an excess of local pride! However the building did receive national recognition in the 1998 Royal Institute of British Architect's awards. The Jury Comment includes:

"On entering one is aware of a real buzz about this LRC ... Together with student and staff user groups, the design team have produced a building which people working in enjoy and which manifestly works for them."

The LRC is also a landmark in changing the image of libraries. Again to quote the local newspaper:

„Hardly recognisable from traditional images of libraries with their dusty old bookshelves ... Airy, bright and spacious, with spectacular views of Teesside, you'll find all the usual journals, periodicals and books, plus plenty of quiet working areas ... But the 400 electronic work stations are the main feature of the new building providing links to the Internet, remote databases, the Internet, plus video, audio and satellite TV." 
It is the building as a symbol of change that has been used by our Corporate Communications Unit to nationally advertise the University. Photographs of the building are on the front of Conference brochures and the Prospectus. Locally it is known as the Crystal Palace.

The Vice-Chancellor also recognised the importance of this building for the public image of the University. At a late stage in the design a new floor was added to house the University Senior managers and the Governors Board Room. The LRC has become in two years the major building landmark for the University.

Even more telling a survey of local opinion of what was excellent about Middlesbrough stated that the University was more important than the local football club was.

\section{STUDENT BEHAVIOUR}

In designing the LRC we had noted that there had been a marked change in student's preferences as regards their learning environment. A view of the library as a temple of silence was being challenged. It would be simplistic to see this as simply the introduction of computing into the book world; the noise of printers and the clicking of the keyboard. Students wished to work in-groups, demonstrate to colleagues their presentations, and listen to their Walkman while reading. We also wished to provide a building that was not intimidating, but rather welcomed students and was as non-threatening as possible. Michael Argyle had in 1972 written of this need for reassurance:

„Adolescents who have only just formed a tentative self-image, are particularly sensitive to the reaction of others, and are insecure in this sense. People who have changed their social class, their job or their nationality are often in a similar position."

The glass frontage of the building and the atrium is welcoming and we have doubled the number of students using the previous library. The zoning of the building into busy and quiet areas with a minimum of enclosed spaces was designed to enable students to talk with their colleagues but also seek out areas for private study. It is this issue of silent study that has been the source of the majority of complaints about the LRC study environment. One of the outcomes of our annual survey into the services of Library \& Information Services has been the need to enforce quiet study away from the central areas. 
Of a response of $1,04424 \%$ indicated that this was a matter of high importance. More females from every School would like quiet study enforced as is shown in this table:

Table 1

\begin{tabular}{|l|c|c|}
\hline \multicolumn{1}{|c|}{ School } & Males & Females \\
\hline Law, Arts \& Humanities & 16.9 & 29.3 \\
\hline Business Management & 23.5 & 30.2 \\
\hline Computing \& Maths & 19.5 & 21.6 \\
\hline Health & 20.6 & 22.4 \\
\hline Social Sciences & 17.9 & 24.5 \\
\hline Science \& Technology & 27.0 & 39.5 \\
\hline
\end{tabular}

This has been raised by Examination Boards and debated at Academic Board and we have produced guides, videos, and posters to influence student behaviour. This has not been a success and we are now actively considering a Noise Patrol at the beginning of the Academic Year to reinforce silence in the designated areas. The open plan nature of the building and no clear demarcation of the work zones have made the building welcoming but have exacerbated the problem of noise.

What I have described at Teesside is also a recurrent irritant at other UK Universities. Judith Andrews (University of Central England) in March 2000 reported on a survey of 38 institutions. They all described noise as a problem. All respondents said that they tried to control noise. The techniques included Tannoy Announcements, patrols by staff, notices, campaigns, leafleting, use of study carrels, and student quiet patrol. One library had introduced a system of zoning i.e. coloured zones that indicates what their expectations are for that particular area. Mobile phones were a particular problem.

Can „Noise” be „designed out” in such buildings or will we have to rely on sanctions such as fines and barring persistent offenders?

\section{STAFF WORKING ENVIRONMENT}

The Follett Review emphasised the need to build on the merits of the traditional university library and drawing together IT and other information sources to support student learning. The University of Teesside had already in 1993 converged its library, academic computing and audio-visual services into 
one organisational framework and one Director. This was not seen as three different services but was to be developed into one service with a common culture, focussed on educational and research needs. Yet prior to the opening of the new building the staff was scattered throughout the site in task orientated groups with little opportunity to meet and discuss needs or even socialise. Therefore in preparing the LRC brief we wished to have the majority of staff in the one building and seated in open plan offices. This we have achieved and the major task teams are in one open space facing out onto the customer areas. The issue and enquiry desks are the boundary divide between staff and customers. All print, IT and AV resources are issued and guidance offered from these common desks. For example the issue system is used by staff and students to borrow books, laptop computers, and data projectors as well as pay their printing bills and fines. All procurement of books, journals and equipment is the responsibility of one team. The fact that it is sited next to the IT team has facilitated the introduction of new IT based ordering systems and the speedy chasing up of purchases. It is easier to manage projects across task teams when outside of formal meetings they can meet in the common staff room and discuss the newest screensaver on their computers! There is one Intranet for all staff, which provides the latest news, as well as having a social section where birthday greetings are exchanged, goods are sold, and entertainments such as the Christmas Party are planned.

\section{CONCLUSION}

When we opened the Learning Resource Centre in January 1998 we invited representatives from the Community and particularly from the Primary, Secondary and Further Education sectors. We believe our future is bound in with the needs of the local region and that we need them to aspire to continue into Higher Education. One of primary school children helped Mo Mowlam to unveil the plaque with the inscription Access to Knowledge, Imagination \& Learning. Subsequently one of his classmates wrote to me:

„Thank you for letting us go to the University and for sending us the photos. It was a lovely day and I think that Mo Mowlam was very nice. I think Garath enjoyed it very much. Did you watch it on TV? I did."

The school subsequently used the photographs and the work from the day as part of their report to the Government inspectors who determine the quality of schools. 
IAN C. BUTCHART

Carl Rogers has written:

„The goal of education, if we are to survive, is the facilitation of change and learning. The only student who is educated is the student who has learned how to adapt to change; the student who has realised that no knowledge is secure, that only the process of seeking knowledge gives a basis for security."

What I hope I have illustrated in this presentation is that a Learning Resource Centre can facilitate change and learning. It is about more than bricks and glass; it is a symbol that can inspire the growth of Knowledge, Imagination $\mathcal{E}$ Learning.

Ian C. Butchart

Director of Library \& Information Services

University of Teesside

Middlesbrough TS1 3BA, England 